\title{
A transparent, flexible, ion conductive, and luminescent PMMA ionogel based on a Pt/Eu bimetallic complex and the ionic liquid [Bmim] [N(Tf $\left.)_{2}\right] \dagger$
}

\author{
Zai-Lai Xie, ${ }^{a}$ Hai-Bing Xu, ${ }^{b}$ André Geßner, ${ }^{a}$ Michael U. Kumke, ${ }^{a}$ Magdalena Priebe, ${ }^{c}$ Katharina M. Fromm ${ }^{c}$ \\ and Andreas Taubert*ad
}

Transparent, ion-conducting, luminescent, and flexible ionogels based on the room temperature ionic liquid (IL) 1-butyl-3-methylimidazolium bis(trifluoromethane sulfonyl)imide [Bmim][N(Tf) 2 , a PtEu 2 chromophore, and poly(methylmethacrylate) (PMMA) have been prepared. The thermal stability of the PMMA significantly increases with IL incorporation. In particular, the onset weight loss observed at $c a .229^{\circ} \mathrm{C}$ for pure PMMA increases to $305^{\circ} \mathrm{C}$ with IL addition. The ionogel has a high ionic conductivity of $10^{-3} \mathrm{~S} \mathrm{~cm}^{-1}$ at $373 \mathrm{~K}$ and exhibits a strong emission in the red with a long average luminescence decay time of $\tau=890 \mu$ s. The resulting material is a new type of soft hybrid material featuring useful thermal, optical, and ion transport properties.

\section{Introduction}

Ionic liquids (ILs) have attracted attention because of their remarkable physico-chemical properties, including high thermal and chemical stability, non-flammability, high electronic and ionic conductivity, low melting point, high solubilizing power, or negligible vapor pressure. ${ }^{1-4}$ This makes ILs interesting for applications where molecular solvents are not suitable or inefficient, for example due to their high vapor pressure. ${ }^{5-8}$ As a result, the evaluation of ILs as device components in chemical sensors, fuel cells, batteries, etc. is currently being pursued, with promising initial results. ${ }^{9-12}$

For application in a device, however, ILs must be immobilized because they are (by definition) liquid. The matrix must immobilize the IL but should not interfere with the IL properties needed for the device to work. ${ }^{13-18}$ There are essentially two approaches for IL immobilization: (1) chemical attachment of ionic species to a support ${ }^{19,20}$ and (2) the physical fixation of ILs (without covalent linkage) within a polymeric, ${ }^{21-26}$ carbonaceous, ${ }^{15,27}$ or inorganic matrix. ${ }^{28,29}$ The resulting materials have been termed ion-gels or ionogels. ${ }^{13,16,17}$ Ionogels are solid materials, which enable the development of devices combining the

${ }^{a}$ Institute of Chemistry, University of Potsdam, Karl-Liebknecht-Str. 24-25, Building 26, D-14476 Potsdam, Germany.E-mail: ataubert@ uni-potsdam.de; Tel: +49 (0)3319775773

${ }^{b}$ New Materials $R \& D$ Center, Institute of Chemical Materials, Chinese Academy of Engineering Physics, Chengdu 621900, China

'Department of Chemistry, University of Fribourg, CH-1700 Fribourg, Switzerland

${ }^{d}$ Max-Planck-Institute of Colloids and Interfaces, D-14476 Potsdam, Germany

$\dagger$ Electronic supplementary information (ESI) available. properties of an IL (e.g. ionic conductivity) and those of the host (e.g. mechanical stability). ${ }^{16,30-32}$

Indeed, ILs confined in a matrix like silica often retain the dynamic features of the liquid IL such as high ionic mobility. ${ }^{15-17}$ The confinement has also been shown to affect the phase behavior of the ILs. For example, Chen et al. have shown that the melting point of 1-butyl-3-methylimidazolium tetrafluoroborate $[\mathrm{Bmim}]\left[\mathrm{BF}_{4}\right]$ increases by $200{ }^{\circ} \mathrm{C}$ if it is confined in a carbon nanotube. This behavior has been assigned to $\pi-\pi$ stacking. ${ }^{27}$ Several studies have demonstrated that properties such as melting points strongly depend on the chemical nature of the pore wall in silica ionogels..$^{29,33-35}$

Lanthanide(III) complexes are interesting for their unique optical, electrical, and magnetic properties. ${ }^{36,37}$ They are potential device components in optical communication, medical diagnostics, etc. Most commonly, molecular compounds (for instance, $\beta$-diketonate complexes) or lanthanide-organic frameworks have been studied. ${ }^{36}$ Recently, d-block chromophores (also known as d-f hybrids) have emerged as promising alternative building blocks for lanthanide-based luminescence. ${ }^{38-42}$ One major reason for the interest is that $\mathrm{d}-\mathrm{f}$ hybrids can cover the entire visible region through appropriate choice of the transition metal ion. ${ }^{39}$ As ILs are good solvents for transition metals, lanthanides, and their complexes, the construction of lanthanidebased ionogels with novel, tailor-made optical or magnetic properties is, in principle, quite straightforward.

Interestingly, there have only been very few reports ${ }^{34,43}$ on this topic, although both magnetic and luminescent lanthanide ILs have been reported. ${ }^{8,34,43-45}$ For example, Tang et al. have described the first luminescent f-element-based IL [Bmim] $\left[\mathrm{Eu}\left(\mathrm{NTf}_{2}\right)_{4}\right]\left(\mathrm{NTf}_{2}=\right.$ bis(trifluoromethane sulfonyl)imide) where the $\mathrm{Eu}(\mathrm{III})$ cation is not surrounded by solvent ligands. ${ }^{8}$ The same group has described the paramagnetic and luminescent IL 
$[\mathrm{Hmim}]_{4}\left[\mathrm{Dy}(\mathrm{SCN})_{7}\left(\mathrm{H}_{2} \mathrm{O}\right)\right] \quad(\mathrm{Hmim}=1$-hexyl-3-methylimidazolium). ${ }^{45}$ Binnemans and Nockemann have reported low-melting lanthanide-containing ILs, namely, $[\text { Emim }]_{x-3}\left[\operatorname{Ln}(\mathrm{NCS})_{x}\left(\mathrm{H}_{2} \mathrm{O}\right)_{y}\right] \quad($ Emim $=1$-ethyl-3-methylimidazolium, $x=6-8, y=0-2, \mathrm{Ln}=\mathrm{Y}, \mathrm{La}, \mathrm{Pr}, \mathrm{Nd}, \mathrm{Sm}, \mathrm{Eu}, \mathrm{Gd}$, $\mathrm{Tb}, \mathrm{Ho}, \mathrm{Er}, \mathrm{Yb}){ }^{46}$ In terms of lanthanide-containing ionogels, Lunstroot et al. have described flexible luminescent poly(methylmethacrylate) (PMMA) films containing [Hmim] $\left[\mathrm{N}(\mathrm{Tf})_{2}\right]$ and Eu(III) complexes. ${ }^{34,43}$ This is, to the best of our knowledge, the first and so far only example of a lanthanide-containing luminescent ionogel based on a polymer matrix.

In this contribution, we report on the first ionogel containing a d-block chromophore based on platinum and europium. The combination of the chromophore with a PMMA matrix and $[\mathrm{Bmim}]\left[\mathrm{N}(\mathrm{Tf})_{2}\right]$ yields a transparent, flexible, ion conductive, and luminescent ionogel, which is, for example, an interesting candidate for soft organic light emitting diodes.

\section{Experimental section}

\section{Materials}

PMMA $\left(M_{\mathrm{w}}=120000 \mathrm{~g} \mathrm{~mol}^{-1}\right.$, Aldrich), 1-butyl-3-methylimidazolium bis(trifluoromethane sulfonyl)imide ([Bmim] $\left[\mathrm{N}(\mathrm{Tf})_{2}\right]$, IoLiTec), and tetrahydrofuran (THF, Merck) were used as received. The d-block chromophore, $\left[\left(\mathrm{Bu}_{2}^{t} \mathrm{bpy}\right)\right.$ $\left.\mathrm{Pt}\left(\mathrm{C} \equiv \mathrm{CC}_{6} \mathrm{H}_{4} \mathrm{tpy}\right)\right]\left[\mathrm{Eu}(\mathrm{hfac})_{3}\right]_{2}\left(\mathrm{PtEu}_{2}\right.$, Scheme 1), was synthesized according to a published procedure. ${ }^{47}$

\section{Ionogels}

Ionogels were prepared by mixing $[\mathrm{Bmim}]\left[\mathrm{N}(\mathrm{Tf})_{2}\right](0.200 \mathrm{~g})$ and $\mathrm{PtEu}_{2}(0.005 \mathrm{~g})$ with a solution of PMMA $(0.500 \mathrm{~g})$ in $10 \mathrm{~mL}$ of THF. The yellow, transparent, and viscous mixture was cast in Petri dishes and allowed to dry for $24 \mathrm{~h}$ at room temperature followed by drying under vacuum for several days.

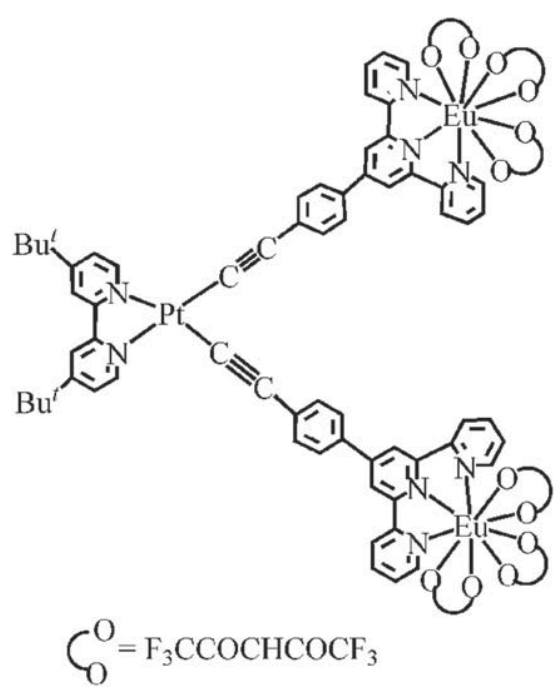

Scheme 1 The d-block chromophore $\left[\left(\mathrm{Bu}_{2}^{t} \mathrm{bpy}\right) \operatorname{Pt}\left(\mathrm{C} \equiv \mathrm{CC}_{6} \mathrm{H}_{4}\right.\right.$ tpy $\left.)\right]$ $\left[\mathrm{Eu}(\mathrm{hfac})_{3}\right]_{2}$ used in this study.

\section{Thermal analysis}

Thermogravimetric analysis (TGA) was done in air on a Linseis L 81 thermal balance from 20 to $900{ }^{\circ} \mathrm{C}$ and a Mettler Toledo TGA/SDTA $851 \mathrm{e}$ from $25^{\circ} \mathrm{C}$ to $800{ }^{\circ} \mathrm{C}$. Heating rate was $10{ }^{\circ} \mathrm{C}$ $\mathrm{min}^{-1}$. Differential scanning calorimetry (DSC) was done on a Netzsch NDSC 204 F1 Phoenix. Samples of $c a .10 \mathrm{mg}$ were placed in aluminium pans with pierced lids. Two heating and cooling cycles from -100 to $150{ }^{\circ} \mathrm{C}$ were run at $10{ }^{\circ} \mathrm{C} \mathrm{min}^{-1}$. Isothermal times were $20 \mathrm{~min}$.

\section{Ionic conductivity measurements}

Ionic conductivities were determined using the complex impedance method by varying the temperature from 293 to $252 \mathrm{~K}$, then from 252 to $343 \mathrm{~K}$, and finally from 343 to $293 \mathrm{~K}$. Alternatingcurrent (ac) conductivity measurements were carried out on a Solartron 1170 frequency response analyzer from $10 \mathrm{~Hz}$ to $1 \mathrm{MHz}$. The perturbation amplitude was $1.5 \mathrm{~V}$. Ten points per decade were measured. The conductivity $(\sigma)$ was determined from Arrhenius plots $(\log (\sigma \mathrm{t})$ vs. 1000/T).

\section{Spectroscopy}

IR spectra were recorded in attenuated total reflection (ATR) mode on a Thermo Nicolet FT-IR Nexus 470. UV/Vis spectra were recorded on an Agilent 8453 or a Perkin-Elmer Lambda 25 UV-Vis spectrometer at room temperature. Solution NMR was measured on a Bruker Avance 300 with tetramethylsilane as internal standard.

\section{Photoluminescence (PL) measurement and analysis}

Steady-state emission and excitation spectra in the UV-Vis region were recorded on a Perkin-Elmer LS 55 luminescence spectrometer with an R928 photomultiplier and a Jobin-Yvon Fluoromax-4 spectrometer at ambient temperature. Luminescence decay times of the pure $\mathrm{PtEu}_{2}$ complex were obtained with an Edinburgh Instruments Xe900 $450 \mathrm{~W}$ pulsed xenon lamp as the excitation light source.

Time-resolved emission spectra (TRES) were recorded using a wavelength-tunable Nd:YAG-laser/OPO system (Spectra Physics/GWU) operated at $20 \mathrm{~Hz}$ as excitation light source and an intensified CCD camera coupled to a spectrograph (MS257 Model 77700A, Oriel Instruments) as detection system. TRES were collected using the box car technique. In a typical experiment the $\mathrm{Eu}(\mathrm{III})$ ion was excited at $\lambda_{\mathrm{ex}}=394 \mathrm{~nm}$ (direct excitation) or $\lambda_{\mathrm{ex}}=310 \mathrm{~nm}$ (indirect excitation). The initial gate delay $\Delta t_{\mathrm{d}}$ (initial delay after laser pulse) was $300 \mathrm{~ns}$ and the gate width $\Delta t_{\mathrm{w}}=10 \mu \mathrm{s}$. The time range for the collection of the emission spectra is defined by the setting of the gate step $\Delta t_{\mathrm{s}}$. The gate step was adjusted depending on the sample such that at the last measurements the luminescence intensity was zero. This assures that the entire luminescence decay can be extracted from the TRES.

The spectrograph is equipped with two different gratings offering different spectral resolutions (300 lines per $\mathrm{mm}$ and 1200 lines per $\mathrm{mm}$, respectively). PL was either detected between $500 \mathrm{~nm}<\lambda_{\text {em }}<750 \mathrm{~nm}$ (spectral resolution of $\sim 0.3 \mathrm{~nm}$ ) or $575 \mathrm{~nm}<\lambda_{\text {em }}<630 \mathrm{~nm}$ (spectral resolution of $\left.\sim 0.1 \mathrm{~nm}\right)$. PL 
decays were obtained by integrating the luminescence intensity of a single luminescence transition. Integration borders were selected to cover the whole luminescence of the transition with minimized interfering intensity from overlapping other transitions. PL decays were fitted with a (multi)exponential function $f(t)$ with a commercial software (FAST Software, Edinburgh Instruments) using eqn (1)

$$
f(t)=\sum_{i=1}^{n} A_{i} \exp \left(\frac{-t}{\tau_{i}}\right)+B
$$

where $t$ is the time after the laser pulse, $A_{i}$ is the decay amplitude, $B$ is a constant (the baseline offset due to background signal), and $\tau_{i}$ is the luminescence decay time. The average decay times, $\langle\tau\rangle$, were calculated using eqn (2),

$$
\langle\tau\rangle=\sum_{i=1}^{n} A_{i} \tau_{i}^{2} / \sum_{i=1}^{n} A_{i} \tau_{i}
$$

The contribution $X_{i}$ of a single decay time $\tau_{i}$ to the whole luminescence decay is given by eqn (3):

$$
X_{i}=\frac{A_{i} \tau_{i}}{\sum_{j=1}^{z} A_{j} \tau_{j}}
$$

Time resolved area-normalized emission spectra (TRANES) were constructed by normalizing the area of the transition of interest to the same value for TRES at different times $t$ after the laser pulse. The resulting spectra were averaged (up to 30 spectra) and smoothed (moving average of 10 points). Isoemissive points $\left(\delta I_{\mathrm{N}}(\nu, t) / \delta t=0 ; I_{\mathrm{N}}(\nu, t)\right.$ is the normalized luminescence intensity) in the TRANES indicate the existence of more than one emissive species or state. ${ }^{48-50}$

TRES or TRANES also enable the investigation of the timedependence of the asymmetry ratio $R$, which is defined by the ratio of two luminescence transitions according to eqn (4). The luminescence transitions are of electric and magnetic dipole character. The electric dipole transition ${ }^{5} \mathrm{D}_{0}-{ }^{7} \mathrm{~F}_{2}$ is "hypersensitive" and reflects changes in the complex symmetry as well as changes in the polarizability of the ligands in the first coordination sphere. In eqn (4) $I$ is the integrated luminescence intensity of the transition indicated by the subscript,

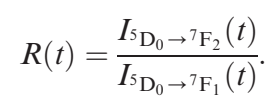

\section{Results}

Ionogels were prepared by dissolving $\mathrm{PtEu}_{2}$ (Scheme 1) in $[\mathrm{Bmim}]\left[\mathrm{N}(\mathrm{Tf})_{2}\right]$, followed by immobilization of the mixture in PMMA. All ionogels contain ca. $30 \mathrm{wt} \%$ of IL, as this IL weight content yields stable materials. The resulting ionogels are transparent, flexible, and show a bright red luminescence typical of Eu(III) upon irradiation at $365 \mathrm{~nm}$, Fig. 1. The uniform emission throughout the sample shows that the chromophore is well dispersed, yielding a uniform material. The purity of the materials is further confirmed by the fact that the UV/Vis spectra essentially only show bands that can be assigned to the $\mathrm{d}-\mathrm{f}$ hybrid chromophore (Fig. S1†).

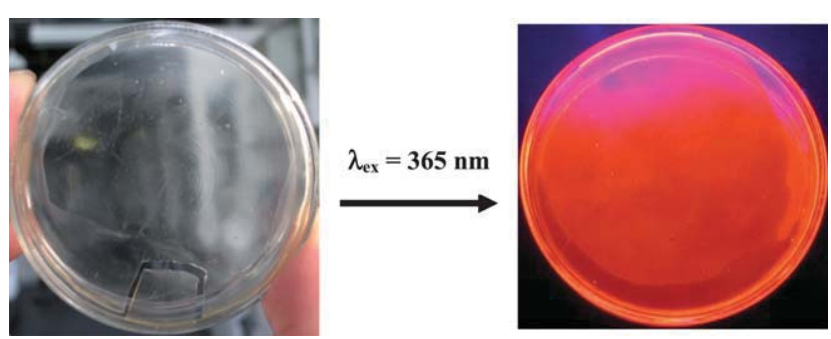

Fig. 1 Photographs of an ionogel in daylight and under UV irradiation.

Fig. 2 shows IR spectra of pure [Bmim][N(Tf $\left.)_{2}\right]$, pure PMMA, and an ionogel. The bands at 3162 and $3123 \mathrm{~cm}^{-1}$ are assigned to the $\mathrm{C}-\mathrm{H}$ vibrations of cyclic $[\mathrm{Bmim}]^{+}$and bands at 2990,829 , and $736 \mathrm{~cm}^{-1}$ are assigned to aliphatic $\mathrm{C}-\mathrm{H}$ vibrations of the side chain of the $[\mathrm{Bmim}]^{+}$cation. The band at $1566 \mathrm{~cm}^{-1}$ stems from $\mathrm{C}-\mathrm{C}$ and $\mathrm{C}-\mathrm{N}$ bending vibrations in $[\mathrm{Bmim}]\left[\mathrm{N}(\mathrm{Tf})_{2}\right]$. The signal at $1344 \mathrm{~cm}^{-1}$ is assigned to the asymmetric stretching mode of $-\mathrm{S}=\mathrm{O}$ in $\left[\mathrm{N}(\mathrm{Tf})_{2}\right]^{-}$. Spectra of pure PMMA show a strong band at $1724 \mathrm{~cm}^{-1}$ from the PMMA carbonyl group. The bands at $2950,2925,1434,1238,958,838$, and $746 \mathrm{~cm}^{-1}$ are assigned to aliphatic C-H vibrations. The bands at 1270, 1140, and $983 \mathrm{~cm}^{-1}$ are assigned to $\mathrm{C}-\mathrm{O}-\mathrm{C}$ stretching vibrations of PMMA. IR spectra of the ionogel show bands of both PMMA and IL indicating successful ionogel formation.

Fig. 3 shows representative thermal analysis data. Differential scanning calorimetry (DSC) of the ionogel only shows a single glass transition with an onset temperature of $30^{\circ} \mathrm{C}$. This is lower than the glass transition temperature $\left(T_{\mathrm{g}}\right)$ of pure PMMA (110 $\left.{ }^{\circ} \mathrm{C}\right)$ and higher than the $T_{\mathrm{g}}$ of the pure IL $\left(-87^{\circ} \mathrm{C}\right) .{ }^{29}$ The fact that only one $T_{\mathrm{g}}$ is observed confirms that the ionogel is homogeneous and that no microphase separation occurs. This is consistent with earlier examples of PMMA ionogel based on $[\mathrm{Bmim}]\left[\mathrm{FeCl}_{4}\right] .^{51}$

Thermogravimetric analysis (TGA) of pure PMMA shows two steps. At $c a .150{ }^{\circ} \mathrm{C}$ a weight loss of $c a .3 \%$ indicates the loss of residual solvent or water taken up from the air. The main PMMA decomposition begins at $229^{\circ} \mathrm{C}$, leaving essentially no residue at $c a .400{ }^{\circ} \mathrm{C}$. The pure IL decomposes in one broad step

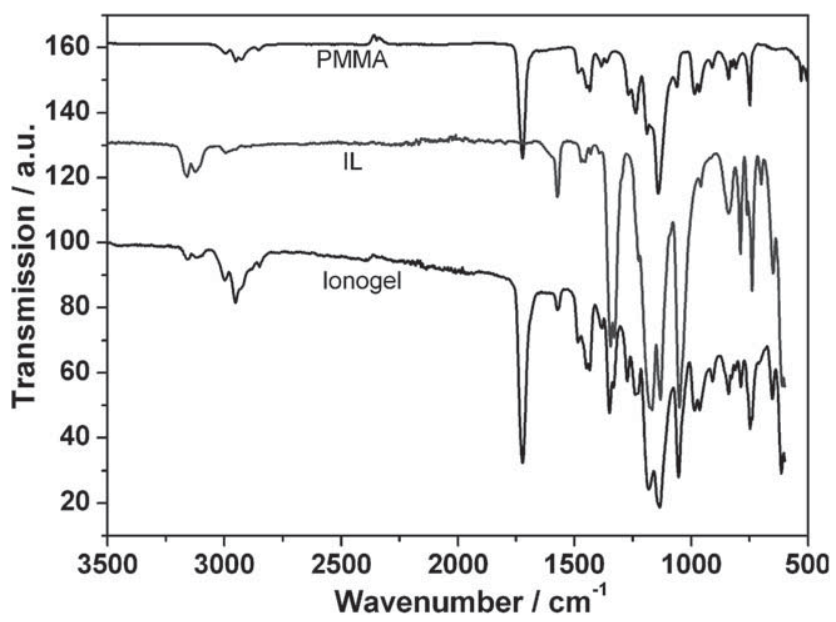

Fig. 2 IR spectra of pure [Bmim][N(Tf $\left.)_{2}\right]$, pure PMMA, and an ionogel with $c a$. $30 \%$ of IL/chromophore mixture. 

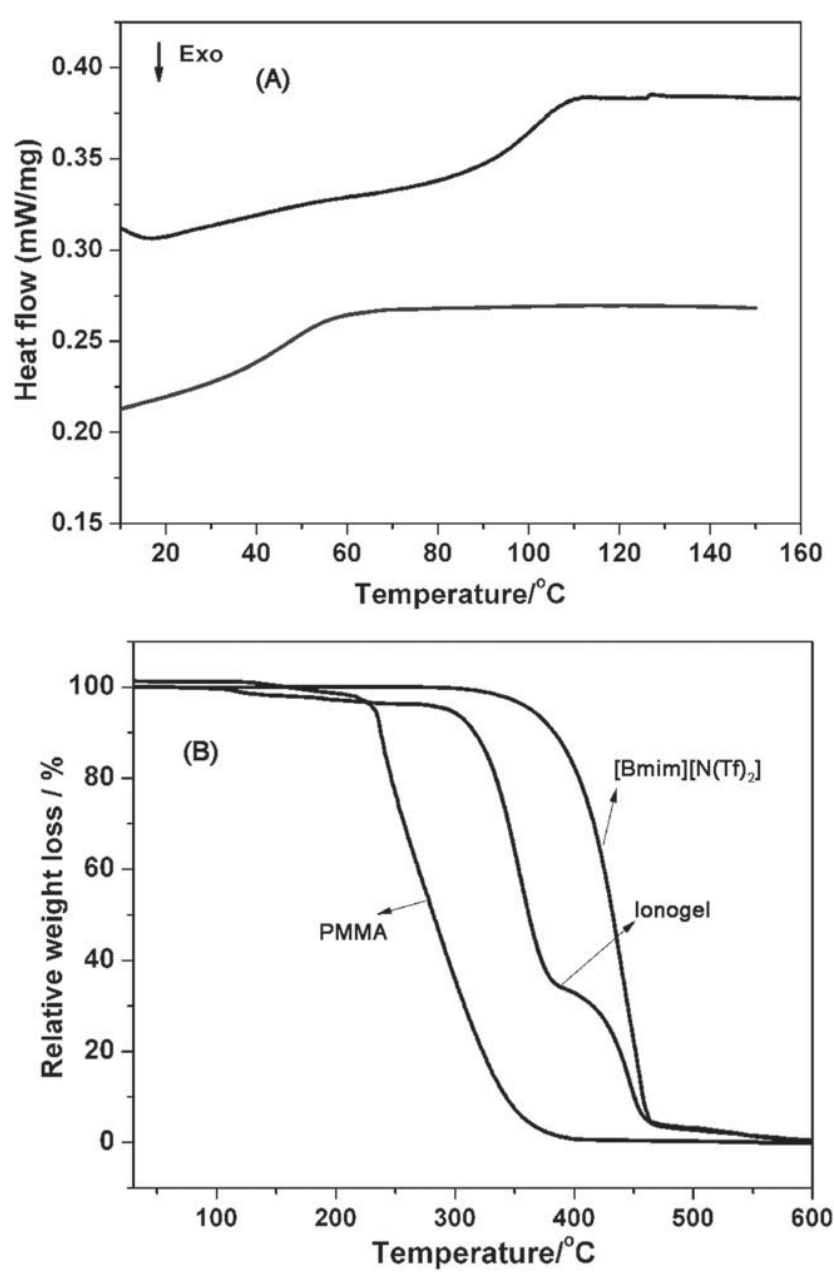

Fig. 3 (A) DSC traces of PMMA (top) and an ionogel (bottom). Heating rate is $10{ }^{\circ} \mathrm{C} \min ^{-1}$ in both cases. For full DSC trace of an ionogel, see Fig. S2†.

between ca. 350 and $460{ }^{\circ} \mathrm{C}$. This process is followed by a tapering off until $600{ }^{\circ} \mathrm{C}$. In contrast to PMMA and the IL,,$^{52,53}$ the ionogel shows four separate weight losses. The first weight loss between $c a$. 120 and $180{ }^{\circ} \mathrm{C}$ is again due to some solvent or water loss. The following two decomposition steps occur at higher temperatures than the decomposition of pure PMMA (305 and 385 instead of $229^{\circ} \mathrm{C}$ ). The relative intensity of these two weight losses is proportional to the weight fraction of PMMA and IL in the ionogel, respectively. TGA thus shows that the IL significantly increases the thermal stability of PMMA ionogel in dynamic TGA, similar to earlier work. ${ }^{51,53}$ The final weight loss is identical to the tapering off above $600{ }^{\circ} \mathrm{C}$ observed in the pure IL.

Fig. 4 shows the ionic conductivities $(\sigma)$ of an ionogel and pure PMMA between 0 and $100{ }^{\circ} \mathrm{C}$. $\sigma$ of the ionogel reaches $10^{-3} \mathrm{~S}$ $\mathrm{cm}^{-1}$ at $373 \mathrm{~K}\left(100^{\circ} \mathrm{C}\right)$ and is, not surprisingly, much higher than $\sigma$ of pure PMMA $\left(10^{-10} \mathrm{~S} \mathrm{~cm}^{-1}\right)$. The Arrhenius plots of the temperature dependence of $\sigma$ can be fitted with the VogelTamman-Fulcher (VTF) equation for the conductivity of electrolytic materials (Fig. S3†). The VTF equation is

$$
\sigma=\sigma_{0} \exp \left[-B /\left(T-T_{0}\right)\right]
$$

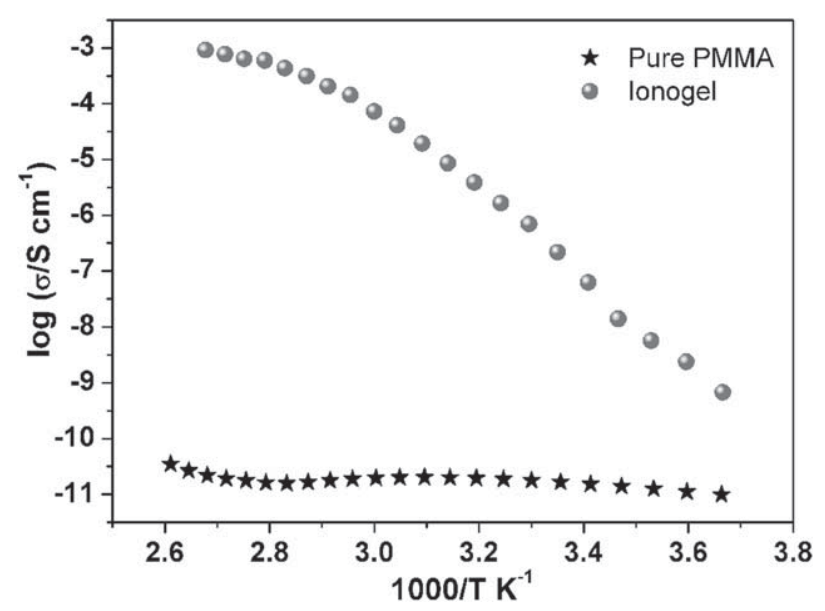

Fig. 4 Temperature dependence of ionic conductivity $\sigma$ for PMMA and an ionogel.

where the $\sigma_{0}\left(\mathrm{~S} \mathrm{~cm}^{-1}\right), B(\mathrm{~K}), T$, and $T_{0}(\mathrm{~K})$ are adjustable parameters.

Fig. 5 shows the excitation $\left(\lambda_{\mathrm{em}}=616 \mathrm{~nm}\right)$ and emission spectra $\left(\lambda_{\mathrm{ex}}=360 \mathrm{~nm}\right)$ of the $\mathrm{PtEu}_{2}$ complex. The excitation spectrum shows a broad band centered at $c a .400 \mathrm{~nm}$, which most likely arises from the $\mathrm{d}_{\pi}(\mathrm{Pt}) \rightarrow \pi^{*}\left(\mathrm{Bu}_{2}{ }_{2} \mathrm{bpy}\right)$ metal-to-ligand charge transfer (MLCT). ${ }^{54,55}$ Upon excitation in the Pt(II)-based MLCT absorption region, one observes a typical Eu(III) emission (Fig. 5). In addition, the Pt(II) chromophore-based ${ }^{3}$ [MLCT] emission in the visible region disappears. This is likely due to an efficient energy transfer from the d-block energy donor to europium. These facts suggest that the sensitized europium luminescence is achieved via the $\operatorname{Pt}\left(\mathrm{Bu}_{2}^{t}\right.$ bpy $)$ fragment operating as a light harvester through rapid and efficient $\mathrm{d} \rightarrow \mathrm{f}$ energy transfer. An asymmetry ratio of $R=14.1$ can be calculated from the emission spectrum. The luminescence decay time $\tau$ of the $\mathrm{PtEu}_{2}$ complex is in the micro- to millisecond range ( $\tau=407 \mu \mathrm{s}$ in the solid state, and $\tau=697 \mu$ s in degassed dichloromethane solution, $\lambda_{\mathrm{ex}}=420 \mathrm{~nm}, \lambda_{\mathrm{em}}=614 \mathrm{~nm}$ ) at ambient temperature.

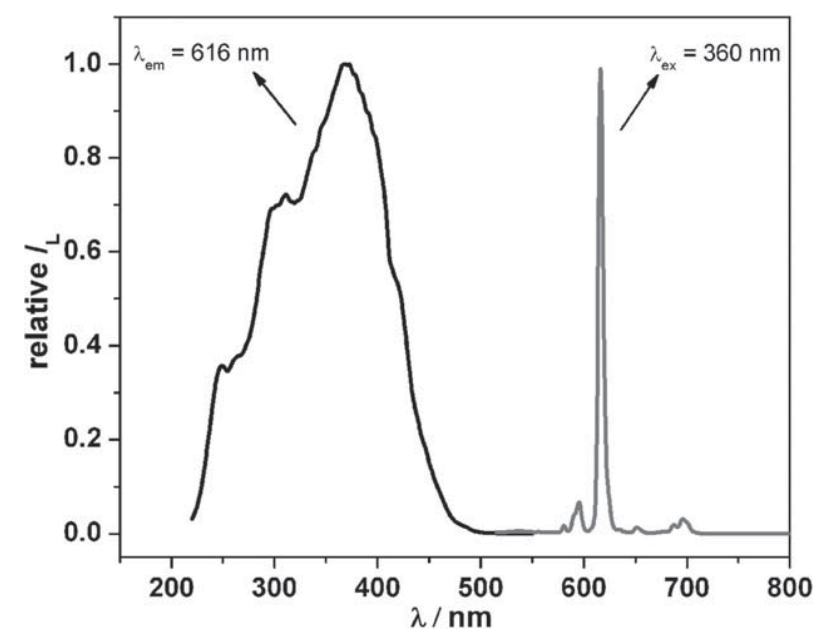

Fig. 5 Excitation (black) and emission (gray) spectra of the $\mathrm{PtEu}_{2}$ complex in dichloromethane. 


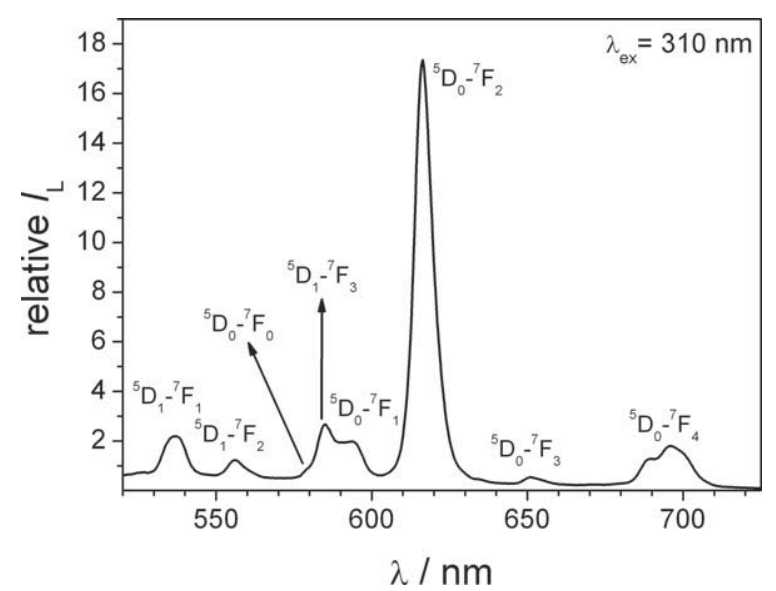

Fig. 6 Photoluminescence spectrum of the $\mathrm{PtEu}_{2}$-ionogel. For excitation spectrum, see Fig. S4†.

Fig. 6 shows a representative emission spectrum of an ionogel excited at $\lambda_{\mathrm{ex}}=310 \mathrm{~nm}$ showing the typical Eu(III) line-like emission. The ${ }^{5} \mathrm{D}_{1} \rightarrow{ }^{7} \mathrm{~F}_{\mathrm{J}}(J=1,2,3)$ transitions are observed at 536,556 , and $585 \mathrm{~nm}$, the ${ }^{5} \mathrm{D}_{0} \rightarrow{ }^{7} \mathrm{~F}_{\mathrm{J}}(J=0,1,2,3,4)$ transitions at $579,592,616,651$, and $697 \mathrm{~nm}$. They are in good agreement with the europium emission observed for the parent chromophore (Fig. 5). No emission from the $\left(\mathrm{Bu}_{2}^{t} \mathrm{bpy}\right) \mathrm{Pt}\left(\mathrm{C} \equiv \mathrm{CC}_{6} \mathrm{H}_{4}\right.$ tpy) moiety was found. This indicates that the efficient energy transfer from the d-block moieties to the Eu(III) ions found for the parent compound is also present in the ionogel. The asymmetry ratio $R$ is around 8.5 , which is characteristic of a non-centrosymmetric, low symmetry coordination geometry around the Eu(III) ion. ${ }^{56}$

The Eu(III) luminescence of the ionogel shows a non-monoexponential decay upon direct $\left(\lambda_{\mathrm{ex}}=394 \mathrm{~nm}\right)$ and indirect excitation $\left(\lambda_{\mathrm{ex}}=310 \mathrm{~nm}\right)$, Fig. 7. Four exponentials were needed for proper fitting of the luminescence decays. The luminescence decay following the direct excitation at $\lambda_{\mathrm{ex}}=394 \mathrm{~nm}$ is considerably faster than the decay following the indirect excitation at $\lambda_{\text {ex }}=310 \mathrm{~nm}$. This is reflected in the average decay times $\langle\tau\rangle_{394 \mathrm{~nm}} \approx 670 \mu \mathrm{s}$ and $\langle\tau\rangle_{310 \mathrm{~nm}} \approx 890 \mu$ s (see also Table 1 ).

Two short decay components of $\tau_{1} \approx 1.4 \mu$ s and $14 \mu \mathrm{s} \leq \tau_{2} \leq$ $20 \mu$ s together account for less than $5 \%$ of the overall luminescence. These decay components may be attributed to a fast decaying background emission and to emission from the ${ }^{5} \mathrm{D}_{1^{-}}$state of Eu(III). The two main components of the luminescence
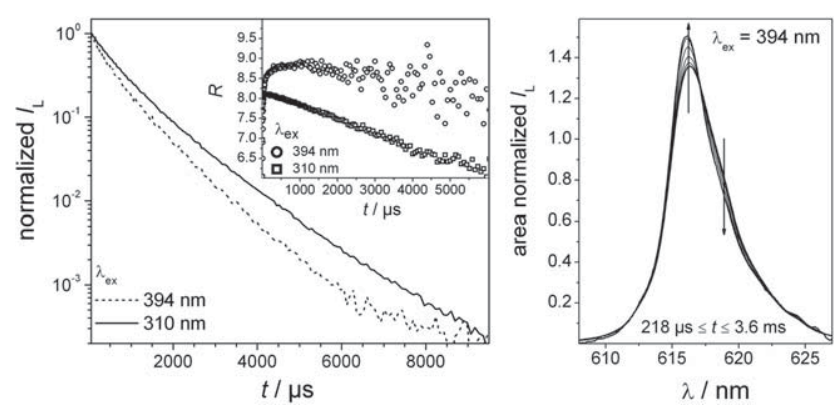

Fig. 7 Photoluminescence decays $\left({ }^{5} \mathrm{D}_{0} \rightarrow{ }^{7} \mathrm{~F}_{1}\right.$-transition) and timedependent asymmetry ratio $R$ of an ionogel (left). TRANES of the ${ }^{5} \mathrm{D}_{0} \rightarrow$ ${ }^{7} \mathrm{~F}_{2}$-transition, $\lambda_{\mathrm{ex}}=394 \mathrm{~nm}$ (right). decays show decay times of $\tau_{3} \approx 270 \mu \mathrm{s}, \tau_{4} \approx 840 \mu \mathrm{s}\left(\lambda_{\mathrm{ex}}=\right.$ $394 \mathrm{~nm}), \tau_{3} \approx 490 \mu \mathrm{s}$, and $\tau_{4} \approx 1140 \mu \mathrm{s}\left(\lambda_{\mathrm{ex}}=310 \mathrm{~nm}\right)$, respectively.

The necessity of fitting the luminescence decays with two main components is supported by the occurrence of a time-dependent asymmetry ratio $R$ (see inset in Fig. 7). Upon excitation at both wavelengths a fast rise in $R v s$. time is observed. This is due to the fast decay of the ${ }^{5} \mathrm{D}_{1}$-luminescence, in particular via the ${ }^{5} \mathrm{D}_{1} \rightarrow$ ${ }^{7} \mathrm{~F}_{3}$-transition which overlaps with the ${ }^{5} \mathrm{D}_{0} \rightarrow{ }^{7} \mathrm{~F}_{1}$-transition. Following the initial rise, $R$ decreases more $\left(\lambda_{\mathrm{ex}}=310 \mathrm{~nm}\right)$ or less $\left(\lambda_{\mathrm{ex}}=394 \mathrm{~nm}\right)$ rapidly. This behavior of $R$ is a strong indicator for a heterogeneous $\mathrm{Eu}(\mathrm{III})$ distribution in the ionogel, where the $\mathrm{Eu}(\mathrm{III})$ is embedded in different microenvironments.

To further support this finding, time-resolved area-normalized emission spectra (TRANES) were constructed. The TRANES of the TRES (for $\lambda_{\mathrm{ex}}=310 \mathrm{~nm}$ and $394 \mathrm{~nm}$, respectively) show isoemissive points in different time domains (see e.g. the long time domain ( $\lambda_{\text {ex }}=394 \mathrm{~nm},{ }^{5} \mathrm{D}_{0} \rightarrow{ }^{7} \mathrm{~F}_{2}$-transition) in Fig. 7 (right)). The change in the luminescence spectra at short times after the laser pulse $(0.3 \mu \mathrm{s} \leq t \leq 218 \mu \mathrm{s})$ is due to the decay of the europium luminescence originating from the ${ }^{5} \mathrm{D}_{1}$ state. In the later time domain $(218 \mu \mathrm{s} \leq t \leq 3.6 \mathrm{~ms})$ small spectral changes with time can be found, which are indicative of the existence of two emitting europium species. ${ }^{57}$ To evaluate the contribution of these two species, a global fit for the decays of both excitation wavelengths was performed, with the decay times set as global parameters. The global fit yields the decay times $\tau_{1} \approx 1.5 \mu \mathrm{s}, \tau_{2} \approx$ $20 \mu \mathrm{s}, \tau_{3} \approx 450 \mu \mathrm{s}$ and $\tau_{4} \approx 1100 \mu \mathrm{s}$, which are in good agreement with the decay times obtained from the discrete fitting analysis (Table 1). Again the two short components account for less than $5 \%$ of the overall luminescence intensity. Upon direct excitation at $\lambda_{\mathrm{ex}}=394 \mathrm{~nm}$, the $450 \mu$ s component makes up for about $57 \%$ and the $1100 \mu$ s for about $39 \%$ of the total luminescence. In contrast, upon excitation at $\lambda_{\mathrm{ex}}=310 \mathrm{~nm}$, the $450 \mu \mathrm{s}$ component only accounts for about $34 \%$ and the $1100 \mu \mathrm{s}$ component for about $66 \%$ of the total luminescence. Due to an improved selectivity in the excitation of $\mathrm{Eu}(\mathrm{III})$ ions that are coordinated to the terpyridyl ligand, their contribution to the overall luminescence is increased, which is reflected in the change of the corresponding amplitudes.

\section{Discussion}

The combination of ILs with polymers enables, in principle, the fabrication of an almost unlimited number of different ionogels. Task-specific ILs (TSILs), such as optically, electrochemically, catalytically, or magnetically active ILs, or an IL solution containing a functional moiety further broaden the scope and

Table 1 Decay times and fractions of decay components of the entire luminescence decays $\left({ }^{5} \mathrm{D}_{0} \rightarrow{ }^{7} \mathrm{~F}_{1}\right.$-transition) obtained from fitting.

\begin{tabular}{lllllll}
\hline \multirow{2}{*}{ Fit } & $\lambda_{\mathrm{ex}} / \mathrm{nm}$ & $\begin{array}{l}\tau_{1} / \mu \mathrm{s} \\
\left(X_{1}(\%)\right)\end{array}$ & $\begin{array}{l}\tau_{2} / \mu \mathrm{s} \\
\left(X_{2}(\%)\right)\end{array}$ & $\begin{array}{l}\tau_{3} / \mu \mathrm{s} \\
\left(X_{3}(\%)\right)\end{array}$ & $\begin{array}{l}\tau_{4} / \mu \mathrm{s} \\
\left(X_{4}(\%)\right)\end{array}$ & $\langle\tau\rangle / \mu \mathrm{s}$ \\
\hline Discrete & 310 & $1(<1)$ & $21(<1)$ & $488(38)$ & $1144(61)$ & 890 \\
& 394 & $1(1)$ & $14(3)$ & $272(24)$ & $838(72)$ & 670 \\
Global & 310 & $2(<1)$ & $20(<1)$ & $444(31)$ & $1081(68)$ & 889 \\
& 394 & $2(1)$ & $20(3)$ & $444(55)$ & $1081(41)$ & 694 \\
\hline
\end{tabular}


potential application of ionogels. In the current study we evaluate the potential of a soft, flexible, and luminescent ionogel as a prototype for new functional soft matter with potential application in, for example, soft LEDs. Optical inspection of the ionogel (Fig. 1), IR spectroscopy (Fig. 2), and DSC (Fig. 3) suggest that the materials are homogeneous without macroscopic defects. IR spectroscopy shows a clear overlap of the spectra of the individual components in the spectra of the ionogel. Moreover, there is only one glass transition in DSC indicating the absence of microheterogeneities.

The fact that there is virtually no shift in the IR bands as the IL is incorporated into the PMMA suggests that the interaction between the IL and PMMA is rather weak. ${ }^{51}$ Although there are a few reports on polymer-based ionogels in the literature, there is still a fair bit of uncertainty as far as the IL/polymer matrix interaction is concerned. Lodge has shown that polymeric networks act like a sponge, where the holes are entirely filled with IL. ${ }^{13}$ Watanabe and co-workers have concluded that there are specific interactions between PMMA and the IL anion, which hamper the formation of ion clusters and associates. ${ }^{53}$ Xie et al. have shown that $[\mathrm{Bmim}]\left[\mathrm{FeCl}_{4}\right]$ is homogeneously distributed in PMMA even at high IL weight fractions, suggesting that there is a large miscibility window of the two components. ${ }^{51}$ Binnemans and coworkers have shown that the IL $[\mathrm{Hmim}]\left[\mathrm{N}(\mathrm{Tf})_{2}\right]$ has a positive influence on the photostability of lanthanide complexes. ${ }^{43}$ As ILs are capable of numerous interactions such as ionic, hydrophobic, electrostatic, hydrogen bonding, coordination to metals, and so on, ${ }^{58}$ the stability and homogeneity of ionogels may depend on many factors; these are however so far only poorly understood.

In spite of the open questions with respect to the exact interaction and structure of ILs in (polymer) ionogels, ILs have been shown to increase the thermal stability of ionogels compared to the pure matrix. Watanabe and coworkers have reported a higher thermal stability for PMMA after combination with [Emim] $\left[\mathrm{N}(\mathrm{Tf})_{2}\right]$ than for bulk PMMA. The thermal stability increases from $257^{\circ} \mathrm{C}$ to $285^{\circ} \mathrm{C}$ despite the decreasing $T_{\mathrm{g}}$ with increasing $[$ Emim $]\left[\mathrm{N}(\mathrm{Tf})_{2}\right]$ content..$^{53}$ A similar behavior has also been observed in the ionogels studied here (DSC and TGA, Fig. 3). The onset of the weight loss is $229^{\circ} \mathrm{C}$ for bulk PMMA and close to $305^{\circ} \mathrm{C}$ for PMMA/[Bmim] $\left[\mathrm{N}(\mathrm{Tf})_{2}\right]$ with $30 \%$ of IL. Consistent with earlier work, ${ }^{51,53}$ the decreasing $T_{\mathrm{g}}$ is a clear indication of the good miscibility of the IL with PMMA and demonstrates that the IL acts as a plasticizer. Indeed, imidazolium ILs have been proposed as alternatives for polymer plasticizers to replace more common chemicals such as dialkylphthalates. ${ }^{59}$

The ionic conductivity of the current ionogel is $10^{-6} \mathrm{~S} \mathrm{~cm}^{-1}$ at $30{ }^{\circ} \mathrm{C}$ and $10^{-3} \mathrm{~S} \mathrm{~cm}^{-1}$ at $100{ }^{\circ} \mathrm{C}$ (Fig. 4), similar to other examples. Watanabe and coworkers have reported $\sigma$ values of almost $10^{-5} \mathrm{~S} \mathrm{~cm}^{-1}$ with low $[\operatorname{Emim}]\left[\mathrm{N}(\mathrm{Tf})_{2}\right]$ at $30{ }^{\circ} \mathrm{C} .{ }^{53}$ This behavior has been assigned to the high self-dissociating and iontransporting ability of the IL and the decoupling of the ion transport from polymer segmental motion. ${ }^{53,60-62}$ This is contrary to an example, ${ }^{51}$ where $[\mathrm{Bmim}]\left[\mathrm{FeCl}_{4}\right]$ was used as the electrolyte; this material showed a lower ionic conductivity, which was assigned to stronger anion-cation coupling between the IL components. Lodge and coworkers have shown that ionogels can form via self-assembly of poly(styrene-blockethylene oxide-block-styrene) triblock copolymers in 1-butyl-3-methylimidazolium hexafluorophosphate [Bmim] $\left[\mathrm{PF}_{6}\right]$, where the ionic conductivity of the resulting ionogel reaches $c a .10^{-3} \mathrm{~S} \mathrm{~cm}^{-1}$ at room temperature. ${ }^{22}$ Finally, Elabd et al. have shown that the ionic conductivity is higher if the ionic domains in a diblock copolymer-based ionogel are oriented than when they are not oriented. ${ }^{63,64}$ Overall, the ionic conductivity data of the current ionogel suggest that they are, similar to the examples just discussed, potential electrolyte materials.

When irradiated with UV/Vis light, the ionogel exhibits the typical red europium emission which is mostly attributed to the ${ }^{5} \mathrm{D}_{0} \rightarrow{ }^{7} \mathrm{~F}_{2}$ transition at $615 \mathrm{~nm}$. The asymmetry ratio $R$ of the ${ }^{5} \mathrm{D}_{0} \rightarrow{ }^{7} \mathrm{~F}_{2}$ and ${ }^{5} \mathrm{D}_{0} \rightarrow{ }^{7} \mathrm{~F}_{1}$ transitions in the ionogel is 8.5, which is lower than the value of $R=14.1$ observed for the pure $\mathrm{PtEu}_{2}$ chromophore. Likely, the reason is a relaxation of the Eu(III) coordination sphere upon doping into the IL/PMMA matrix. This is probably due to the fact that the IL is a good solvent for the complex. In combination with the incorporation into PMMA, an effective protection (e.g., less radiationless deactivation via vibrations and a reduced quenching of the ligand triplet state) is achieved. Similarly, Binnemans and coworkers have shown that the intensity ratio $I\left({ }^{5} \mathrm{D}_{0}-{ }^{7} \mathrm{~F}_{2}\right) / I\left({ }^{5} \mathrm{D}_{0}-{ }^{7} \mathrm{~F}_{1}\right)$ of a europium(III) $\beta$-diketonate complex and the corresponding doped PMMA film is different. This was ascribed to the dissociation of the europium(III) tetrakis $\beta$-diketonate complex by coordinating to carbonyl $(\mathrm{C}=\mathrm{O})$ groups of the PMMA matrix, ${ }^{43}$ although this will need to be proven in the future.

The luminescence decay time of the pure $\mathrm{PtEu}_{2}$ complex is $\tau=$ $407 \mu$ s in the solid state, and $\tau=697 \mu$ s in degassed dichloromethane solution $\left(\lambda_{\mathrm{ex}}=420 \mathrm{~nm}, \lambda_{\mathrm{em}}=614 \mathrm{~nm}\right)$, whereas the ionogel exhibits a distinctly longer average decay time of $\langle\tau\rangle=$ $890 \mu$ s (at $\lambda_{\mathrm{ex}}=310 \mathrm{~nm}$ ). Presumably the presence of the ionic liquid yields a more homogeneous distribution of the ionic europium(III) complexes in the PMMA polymer. This results in less closely associated complexes and less quenching of luminescence. In contrast to the monoexponential luminescence decay in pure $\mathrm{PtEu}_{2}$, the luminescence decay of the ionogel is biexponential with two main components of $\tau_{3} \approx 270 \mu$ s and $\tau_{4} \approx$ $840 \mu \mathrm{s}\left(\lambda_{\mathrm{ex}}=394 \mathrm{~nm}\right)$ and $\tau_{3} \approx 490 \mu \mathrm{s}$ and $\tau_{4} \approx 1140 \mu \mathrm{s}\left(\lambda_{\mathrm{ex}}=\right.$ $310 \mathrm{~nm})$. This finding is supported by the TRANES suggesting two emitting europium species. Possibly, this can be ascribed to carbonyl $(\mathrm{C}=\mathrm{O})$ in the PMMA which plays a crucial role and offers additional relaxation paths of luminescence. For example, the Eu(III) complex may partially dissociate in the PMMA matrix, similar to earlier suggestions. ${ }^{43,57}$ In summary, and consistent with literature, the current data show that the combination of IL, chromophore, and polymer directly affects the properties of the final material.

\section{Conclusion}

We have prepared a new type of transparent and luminescent ionogel based on PMMA, [Bmim][N(Tf $\left.)_{2}\right]$, and a d-block chromophore $\left(\mathrm{PtEu}_{2}\right)$. $[\mathrm{Bmim}]\left[\mathrm{N}(\mathrm{Tf})_{2}\right]$ is an efficient solvent for the $\mathrm{PtEu}_{2}$ complex in PMMA. The data show that lanthanide complexes incorporated into a suitable ionogel constitute novel soft materials with multiple useful properties such as transparency, high thermal stability, luminescence, and relatively high ionic conductivity. The optical properties are determined by the interaction and behavior of the chromophore within the 
IL/PMMA matrix. This aspect will however need further study for quantitative understanding. In spite of this, the current report shows that metal complex-doped ionogels are potential electrolytes for use in various devices and candidates for organic light emitting diodes.

\section{Acknowledgements}

We thank Dr F.-P. Wang for help with conductivity measurements, Dr A. Friedrich for TGA measurements, and the Max Planck Institute of Colloids and Interfaces (Colloid Chemistry Department), the University of Potsdam, Deutsche Forschungsgemeinschaft (TA571/3-1), the Fonds der Chemischen Industrie for financial support, the University of Fribourg, FriMat, the Swiss National Science Foundation. Z.L.X. acknowledges a Chinese Science Council Doctoral Fellowship.

\section{References}

1 A. Taubert, Top. Curr. Chem., 2009, 290, 127.

2 K. Yuan and H. Ling, Progr. Chem., 2008, 20, 5.

3 P. Wasserscheid and T. Welton, Ionic Liquids in Synthesis, WileyVCH, Weinheim, 2008

4 R. D. Rogers and K. R. Seddon, Science, 2003, 302, 792.

5 Y. Yoshida and G. Saito, Phys. Chem. Chem. Phys., 2010, 12, 1675.

6 H. Ohno and K. Fukumoto, Chem. Commun., 2006, 3081

7 H. Ohno, Bull. Chem. Soc. Jpn., 2006, 79, 1665.

8 S. Tang, A. Babai and A. V. Mudring, Angew. Chem., Int. Ed., 2008, 47, 7631 .

9 I. Krossing, I. Raabe, K. Wagner, K. Guttsche, M. K. Wang, M. Gratzel and G. Santiso-Quinones, Chem.-Eur. J., 2009, 15, 1966.

10 M. Armand, F. Endres, D. R. MacFarlane, H. Ohno and B. Scrosati, Nat. Mater., 2009, 8, 621.

11 Y. Bai, Y. M. Cao, J. Zhang, M. Wang, R. Z. Li, P. Wang, S. M. Zakeeruddin and M. Gratzel, Nat. Mater., 2008, 7, 626.

12 F. Benito-Lopez, R. Byrne, A. M. Raduta, N. E. Vrana, G. McGuinness and D. Diamond, Lab Chip, 2010, 10, 195.

13 T. P. Lodge, Science, 2008, 321, 50.

14 J. Lee, M. J. Panzer, Y. Y. He, T. P. Lodge and C. D. Frisbie, J. Am. Chem. Soc., 2007, 129, 4532.

15 J. Le Bideau, J. B. Ducros, N. Buchtova, A. Magrez and O. Chauvet, J. Mater. Chem., 2011, 21, 2508.

16 A. Vioux, J. Le Bideau and L. Viau, Chem. Soc. Rev., 2011, 40, 907.

17 A. Vioux, L. Viau, S. Volland and J. Le Bideau, C. R. Chim., 2010, 13, 242 .

18 J. M. Lu, F. Yan and J. Texter, Prog. Polym. Sci., 2009, 34, 431.

19 Y. Xie, K. L. Ding, Z. M. Liu, J. J. Li, G. M. An, R. T. Tao, Z. Y. Sun and Z. Z. Yang, Chem.-Eur. J., 2010, 16, 6687.

20 T. Sasaki, C. M. Zhong, M. Tada and Y. Iwasawa, Chem. Commun., 2005, 2506

21 T. Ueki and M. Watanabe, Macromolecules, 2008, 41, 3739.

22 Y. Y. He, P. G. Boswell, P. Buhlmann and T. P. Lodge, J. Phys. Chem. B, 2007, 111, 4645.

23 Z. H. Li, J. Jiang, G. T. Lei and D. S. Gao, Polym. Adv. Technol., 2006, 17, 604

24 P. Kubisa, Prog. Polym. Sci., 2004, 29, 3.

25 P. Snedden, A. I. Cooper, K. Scott and N. Winterton, Macromolecules, 2003, 36, 4549.

26 R. T. Carlin and J. Fuller, Chem. Commun., 1997, 1345.

27 G. Z. Wu, S. M. Chen, M. L. Sha and S. R. Huang, J. Am. Chem. Soc., 2007, 129, 2416.

28 J. Le Bideau, P. Gaveau, S. Bellayer, M. A. Neouze and A. Vioux, Phys. Chem. Chem. Phys., 2007, 9, 5419.
29 M. A. Neouze, J. Le Bideau, P. Gaveau, S. Bellayer and A. Vioux, Chem. Mater., 2006, 18, 3931.

30 S. K. Nett, G. Kircher and J. S. Gutmann, Macromol. Chem. Phys., 2009, 210, 971.

31 R. Göbel, P. Hesemann, J. Weber, E. Moller, A. Friedrich, S. Beuermann and A. Taubert, Phys. Chem. Chem. Phys., 2009, 11, 3653.

32 F. Gayet, L. Viau, F. Leroux, F. Mabille, S. Monge, J. J. Robin and A. Vioux, Chem. Mater., 2009, 21, 5575.

33 K. Lunstroot, K. Driesen, P. Nockemann, K. Van Hecke, L. Van Meervelt, C. Gorller-Walrand, K. Binnemans, S. Bellayer, L. Viau, J. Le Bideau and A. Vioux, Dalton Trans., 2009, 298.

34 K. Lunstroot, K. Driesen, P. Nockemann, C. Gorller-Walrand, K. Binnemans, S. Bellayer, J. Le Bideau and A. Vioux, Chem. Mater., 2006, 18, 5711.

35 R. Göbel, A. Friedrich and A. Taubert, Dalton Trans., 2010, 39, 603.

36 K. Binnemans, Chem. Rev., 2009, 109, 4283.

37 J. C. G. Bunzli and S. V. Eliseeva, Chem. Soc. Rev., 2010, 39, 189.

38 V. W. W. Yam, K. M. C. Wong and N. Y. Zhu, Angew. Chem., Int. Ed., 2003, 42, 1400

39 M. D. Ward, Coord. Chem. Rev., 2007, 251, 1663.

40 M. D. Ward, T. K. Ronson, T. Lazarides, H. Adams, S. J. A. Pope, D. Sykes, S. Faulkner, S. J. Coles, M. B. Hursthouse, W. Clegg and R. W. Harrington, Chem.-Eur. J., 2006, 12, 9299.

41 V. W. W. Yam, R. P. L. Tang, K. M. C. Wong and K. K. Cheung, Organometallics, 2001, 20, 4476.

42 Z. N. Chen, N. Zhao, Y. Fan and J. Ni, Coord. Chem. Rev., 2009, 253, 1 .

43 K. Lunstroot, K. Driesen, P. Nockemann, L. Viau, P. H. Mutin, A. Vioux and K. Binnemans, Phys. Chem. Chem. Phys., 2010, 12, 1879.

44 A. V. Mudring and S. F. Tang, Eur. J. Inorg. Chem., 2010, 2569.

45 B. Mallick, B. Balke, C. Felser and A. V. Mudring, Angew. Chem., Int. Ed., 2008, 47, 7635 .

46 P. Nockemann, B. Thijs, N. Postelmans, K. Van Hecke, L. Van Meervelt and K. Binnemans, J. Am. Chem. Soc., 2006, 128, 13658.

47 Z. N. Chen, H. B. Xu, L. Y. Zhang, X. M. Chen and X. L. Li, Cryst. Growth Des., 2009, 9, 569.

48 N. Periasamy, A. S. R. Koti and M. M. G. Krishna, J. Phys. Chem. A, 2001, 105, 1767.

49 N. Periasamy, Ira, A. S. R. Koti and G. Krishnamoorthy, J. Fluoresc., 2003, 13, 95 .

50 C. Tiseanu, V. A. Lorenz-Fonfria, V. I. Parvulescu, A. Gessner and M. U. Kumke, J. Appl. Phys., 2008, 104, 033530.

51 Z. L. Xie, A. Jelicic, F. P. Wang, P. Rabu, A. Friedrich, S. Beuermann and A. Taubert, J. Mater. Chem., 2010, 20, 9543.

52 J. Jiang, D. S. Gao, Z. H. Li and G. Y. Su, React. Funct. Polym., 2006, 66, 1141 .

53 M. A. Susan, T. Kaneko, A. Noda and M. Watanabe, J. Am. Chem. Soc., 2005, 127, 4976.

54 S. C. Chan, M. C. W. Chan, Y. Wang, C. M. Che, K. K. Cheung and N. Y. Zhu, Chem.-Eur. J., 2001, 7, 4180.

55 M. Hissler, W. B. Connick, D. K. Geiger, J. E. McGarrah, D. Lipa, R. J. Lachicotte and R. Eisenberg, Inorg. Chem., 2000, 39, 447.

56 J. C. G. Bunzli and C. Piguet, Chem. Soc. Rev., 2005, 34, 1048.

57 R. Y. Gao, C. Koeppen, G. Q. Zheng and A. F. Garito, Appl. Opt., 1998, 37, 7100.

58 H. Weingaertner, Angew. Chem., Int. Ed., 2008, 47, 654

59 M. P. Scott, C. S. Brazel, M. G. Benton, J. W. Mays, J. D. Holbrey and R. D. Rogers, Chem. Commun., 2002, 1370.

60 D. P. Kaur, K. Yamada, J. S. Park and S. S. Sekhon, J. Phys. Chem. $B, 2009,113,5381$

61 B. Singh and S. S. Sekhon, J. Phys. Chem. B, 2005, 109, 16539.

62 W. Xu, E. I. Cooper and C. A. Angell, J. Phys. Chem. B, 2003, 107, 6170.

63 Y. A. Elabd and Y. S. Ye, Polymer, 2011, 52, 1309

64 Y. A. Elabd, H. Chen, J. H. Choi, D. Salas-de La Cruz and K. I. Winey, Macromolecules, 2009, 42, 4809. 